\title{
Revista Viração: um projeto social impresso
}

Cláudia Lago

Doutora em Ciências da Comunicação, professora da Faculdade Anhembi Morumbi

e diretora administrativa da SBPJor.

E-mail: claudiaeducom@yahoo.com.br

Izabel Leão

Especialista em Gestão de Processos Comunicacionais, mestranda em Comunicação e Educação pela ECA/USP, membro do Conselho Editorial da revista Viração

E-mail: mariaiza@usp.br

Com a democratização das instituições e da sociedade brasileira como um todo, ocorrida no final do século XX, conceitos como cidadania e protagonismo tornaram-se referência social. Em que pesem a construção histórica desses conceitos e sua apropriação de forma diferente (e desigual) pelos diversos agentes que deles reivindicam, concretizaram-se enquanto idéias-forças, capazes de mobilizarem grupos sociais e efetivarem políticas públicas, independentes do governo em exercício. Uma rápida pesquisa nas páginas oficiais dos setores públicos da área de educação, por exemplo, dá conta do lugar de destaque ocupado pelos projetos que indicam entre suas metas estimular/discutir/propiciar etc. a cidadania e o protagonismo dos jovens.

A apropriação dos termos e sua utilização generalizada, por assim dizer, concorrem muitas vezes para que nem sempre estes estejam conectados aos conceitos que os geraram. Assim, identificar um projeto como de inclusão cidadã ou de incentivo ao protagonismo não necessariamente significa que ele esteja francamente impregnado das características próprias a esse tipo de projeto - até por conta da dificuldade de se chegar a um consenso sobre essas características e sobre como efetivá-las.

Em relação especificamente ao protagonismo, termo que por si só se presta a inúmeras interpretações, as ações em torno do conceito vão desde um simples perceber que o jovem existe e ouvi-lo, até propostas mais radicais que buscam incorporar o jovem - e a criança - na plenitude de seus direitos; propostas ligadas a uma idéia de

democracia radical que potencia ciudadanos sin excluir a ninguno, no como objetos, sino como sujetos de derecho con capacidad para ejercerlos (incluida la infancia, adolescencia y juventud) no como receptores pasivos de derechos, sino como sujetos activos que autodeterminan su propio civismo ${ }^{1}$.

Nesse sentido, uma das experiências levadas a cabo é a da instituição do Orçamento Participativo Criança, pela Prefeitura Municipal de São Paulo, que

1. MUÑOZ, César. Otras ciudades posibles base de ese otro mundo posible. Artigo disponível em: <http://fmet.terra.com. $\mathrm{br} /$ paineis/cesar_munoz. pdf>. Acesso em: 8 ago. 2004. 
contou com a assessoria de César Muñoz, entre outros. Em que pesem as dificuldades de implantação, um olhar sobre ele pode ser interessante para perceber as direções possíveis do movimento de empoderamento do jovem e da criança pelo poder público.

Em meio a tanta diversidade, acreditamos que a proposta de diferenciação dos projetos e políticas que envolvem a infância, adolescência e juventude, formulada pelo pesquisador catalão César Muñoz, pode ser útil para ajudar a pensar a construção da revista Viração como um projeto que reivindica o protagonismo juvenil. Muñoz identifica três enfoques principais: projetos que partem da idéia de para a infância e juventude (tradicionais, paternalistas e alienantes, apesar de muitas vezes beneficiarem segmentos); os que pensam com ou junto

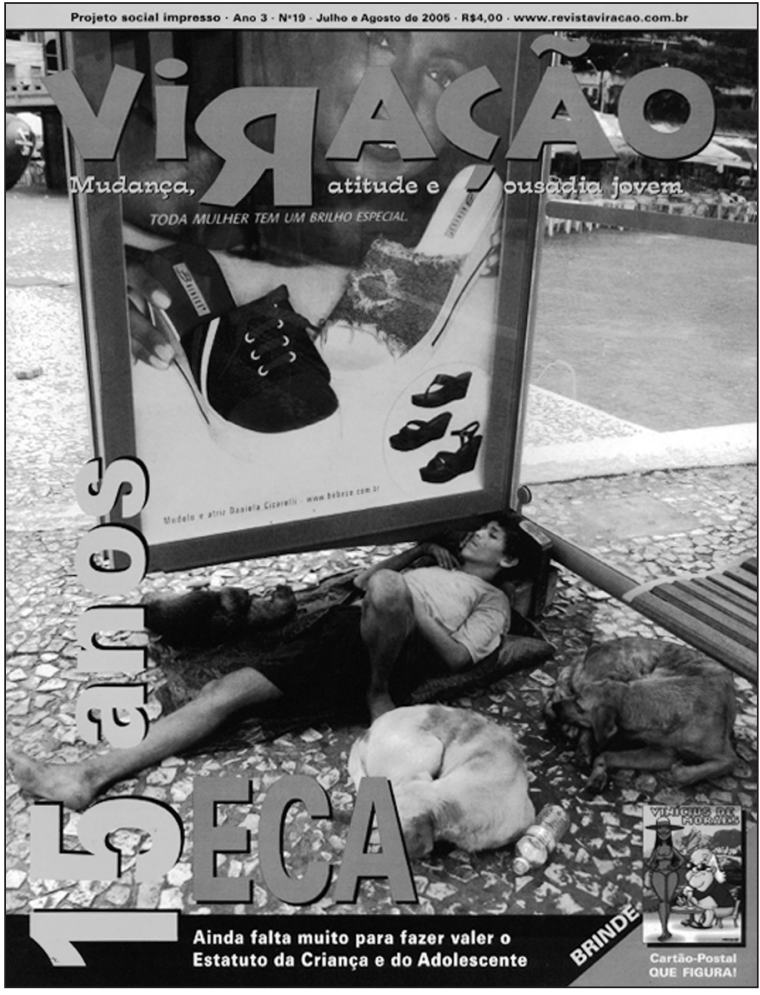
com a infância, adolescência e juventude (são positivos, porém não vão até a raiz da questão); e, finalmente, aqueles (poucos) que, de acordo com seu enfoque, partem das crianças, adolescentes e jovens, ou seja, "propuestas de anteproyectos que se inicien e se realicen DESDE las ideas, criterios, sugerencias, deseos, necesidades, dudas, miedos, certezas... de la infancia, adolescencia e juventud"?.

A perspectiva esboçada por Muñoz adéqua-se aos pressupostos adotados pelo Núcleo de Comunicação e Educação da ECA/USP, ao mapear o campo da educomunicação, sistematizando seus conceitos; desses pressupostos destacamos os de gestão democrática do ambiente educativo (formal ou não), de criação de ecossistemas francos e abertos, de valorização da capacidade de expressão dos envolvidos nos processos sociais, entre outros. Ismar de Oliveira Soares conceitua educomunicação como

o conjunto de ações inerentes ao planejamento, implementação e avaliação de processos, programas e produtos destinados a criar e a fortalecer ecossistemas comunicativos em espaços educativos presenciais ou virtuais, assim como melhorar o coeficiente comunicativo das ações educativas, incluindo as relacionadas ao uso dos recursos da informação no processo de aprendizagem ${ }^{3}$.

A idéia de protagonismo infanto-juvenil radical, como identifica o pesquisador catalão, parece-nos extremamente similar ao ideário de protagonismo defendido e implementado pelo NCE em sua atuação, seja por meio das ações 
de políticas públicas que têm desenvolvido, seja nos estudos que sistematizam e aprofundam os conceitos do campo.

A revista Viração ${ }^{4}$ foi uma iniciativa apoiada pelo NCE, exatamente por ser considerada um projeto educomunicativo, na medida em que é um exemplo da tentativa de constituir o jovem (o adolescente propriamente, não a criança) sujeito de direito, portanto, dentro dos princípios da educomunicação. Iniciado como um projeto para o jovem, hoje oscila entre as perspectivas de construir-se com e a partir de os jovens e adolescentes.

\section{A REVISTA}

A revista Viração, lançada em 2003, tem uma tiragem média de 10 mil exemplares, com 36 páginas impressas em quatro cores, em papel cuchê. Foi criada por um grupo de jornalistas independentes em parceria com o Núcleo de Comunicação e Educação da Escola de Comunicações e Artes da Universidade de São Paulo (NCE-ECA/USP). A partir da iniciativa de Paulo Lima, editor-chefe da publicação e agraciado com o título Jornalista Amigo da Criança ${ }^{5}$, a idéia era criar uma revista para jovens entre 12 e 18 anos, dada a existência de uma lacuna no cenário editorial brasileiro em relação a esse público: a necessidade de um veículo com caráter mais crítico e não mercadológico, tratando os temas de interesse dos jovens com outros enfoques e enquadramentos.

Nesse sentido, a Viração diferencia-se nas formas de contato com seu público-alvo das demais revistas voltadas ao segmento infanto-juvenil de grande tiragem e apelo comercial. A atração é o seu Conselho Editorial Jovem, que se reúne na sede do veículo a cada quinze dias.

A revista Capricho, por exemplo, tem no contato direto com os leitores (correspondência, e-mails etc.) um grande filão para a identificação dos temas interessantes para seu público, bem como para ajudar a definir enfoques e abordagens. Esse sistema também é importante para tecer as redes de relações que darão conta das pautas: quais jovens serão enfocados na coluna meu canto, por exemplo. Por outro lado, a publicação mantém um grupo de jovens - Galera Capricho - que discute a revista, analisa as pautas, a partir de propostas que chegam do grupo de editores. Sua relação é condicionada pelos parâmetros da revista Capricho e a participação encerra-se depois de um período de seis meses. Esse mecanismo nos parece a idéia do fazer para os jovens, oscilando, talvez, para um tímido com os jovens.

O Conselho Editorial Jovem da Viração (apelidado de "Virajovens") está presente em 17 capitais do Brasil - São Paulo, Rio de Janeiro, Curitiba, Porto Alegre, Brasília, Goiânia, Campo Grande, Manaus, São Luís do Maranhão, Fortaleza, Natal, João Pessoa, Maceió, Recife, Salvador, Vitória e Belo Horizonte; inversamente, é uma forma de tentar alcançar uma premissa que acabou por se tornar meta da revista, qual seja, ser feita pelo jovem. É um mecanismo real de participação do leitor não apenas como consumidor do veículo, mas como sujeito que pode interferir intensamente com sugestões, opiniões e, ainda, colaborando na confecção de reportagens e entrevistas.
4. <http://www.revistaviracao.com.br>.

5. Jornalista Amigo da Criança é um diploma concedido pela Agência de Notícias pelos Direitos da Infância (Andi). Disponível em: <http://www. andi.org.br/mini_sites/ jac/>. (N.E.) 
É composto, em média, de 20 a 40 adolescentes, representantes de escolas públicas e privadas, de centros de defesa da criança e do adolescente, participantes de organizações não-governamentais que atuam com o protagonismo juvenil, em medidas socioeducativas, e representantes de movimentos sociais estudantil, negro, ambiental.

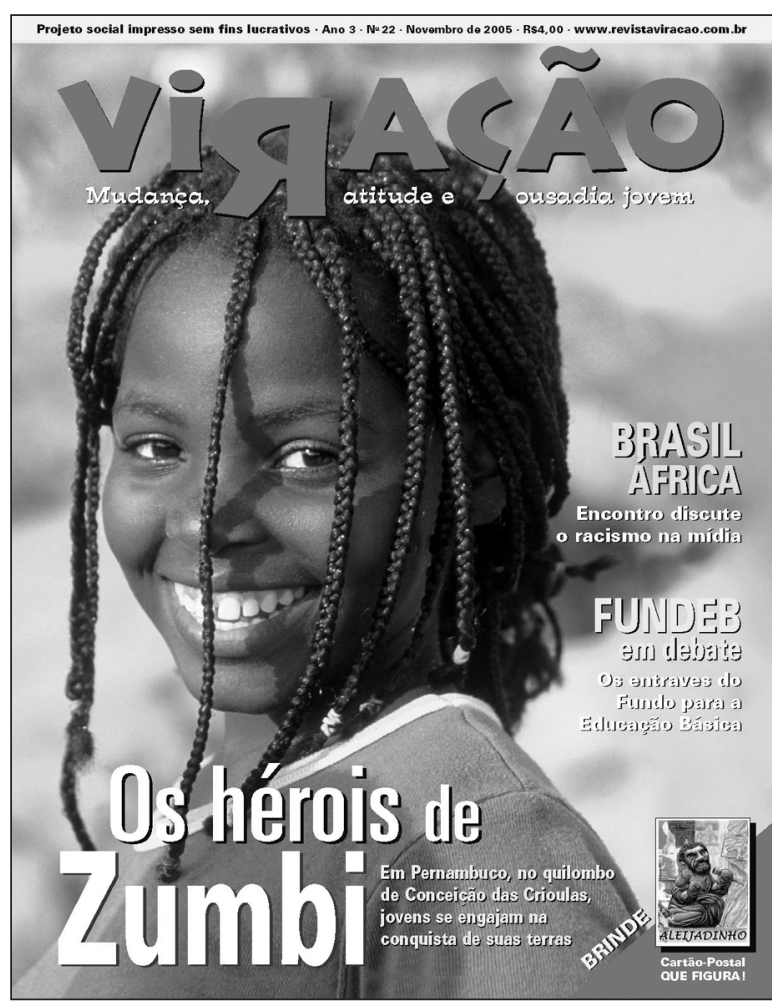

O Conselho Editorial Jovem reúne-se com a equipe profissional para elaborar a pauta, que não é ditada pelo editor ou por jornalistas da redação e colaboradores, mas discutida entre todos. Além disso, nesse momento socializam experiências obtidas com a produção das edições anteriores. A participação no processo garante o protagonismo dentro da revista, ao mesmo tempo em que modifica a própria compreensão dos adultos envolvidos sobre a concepção da pauta.

Foi o que aconteceu com a matéria feita pelo estudante Izael Altino dos Santos, 18 anos, membro da Rede de Jovens Educomunicadores, criada pelo NCE, colaborador ativo da revista e do Conselho Jovem. Izael foi autor da reportagem sobre os riscos do tabagismo à saúde, veiculada em 2004, na qual entrevistou especialistas e jovens. Esse, aliás, foi o diferencial da matéria em relação às que a mídia realiza habitualmente. $\mathrm{O}$ jovem repórter contrapôs as opiniões dos adolescentes que evitam o cigarro e as dos fumantes. Ele passou por todas as etapas: do planejamento da matéria, passando pela pesquisa e checagem de dados até a etapa de redação e edição do material reunido.

Outra adolescente que também faz parte do Conselho Editorial Jovem da Viração é Sara de Araújo Santos, 17 anos, que atua como monitora, na escola, de turmas que utilizam o equipamento de rádio para produção de programas nos intervalos. Em 2004, ela realizou matéria sobre gravidez na adolescência. A sugestão da pauta no Conselho Jovem ocorreu com base na constatação, em sua comunidade, do aumento do número de casos. A partir do problema em um grupo delimitado, ela levantou a discussão que interessa a todas as jovens, independentemente da condição social, do grau de qualidade da escola ou das características do lugar em que vivem. No local, ela encontrou um tema universal.

A dinâmica do processo da revista Viração difere, em muito, de outras publicações, mesmo aquelas consideradas alternativas, pois o Conselho possui 
poderes que vão além da simples avaliação da linha editorial. Ele se reúne mensalmente para fazer uma leitura crítica da comunicação, avaliar a linguagem, o conteúdo e apresentação gráfica da revista, propor pautas e sugerir modalidades para divulgar a proposta do projeto, qual seja, ser um canal de debates sobre o mundo dos jovens e adolescentes, no Brasil e no mundo. Cabe também ao Conselho ajudar nas estratégias de distribuição e venda.

Para se ter uma idéia da importância e centralidade do Conselho Editorial Jovem, basta mencionar que ele tem muito mais espaço de atuação do que o Conselho Editorial (formado por adultos), que, não obstante, atua como órgão consultor do veículo.

Outra forma de se ligar ao jovem, de estar junto dele e conhecê-lo melhor está na escolha dele como fonte, junto de especialistas das áreas enfocadas. Tal estratégia é comum às demais publicações destinadas a esse público; porém, a diferença está em que Viração não se restringe a ouvir o jovem em relação a seu cotidiano (a tônica da maioria dos suplementos), mas também deseja saber sua opinião sobre temas de interesse social diverso (como a pauta sobre loucura, em uma das edições).

No entanto, há que se observar que todo o processo de edição das matérias é coordenado pela equipe fixa (o editor-chefe, a redatora e um assistente). Conta também com a participação voluntária de vários profissionais do meio jornalístico e o apoio institucional de entidades como o Unicef, a Unesco, a Ashoka, a Andi, o NCE-ECA/USP e a Ipaz.

Há uma compreensão geral de que é muito difícil a revista ser realizada inteiramente pelo jovem, que desconhece habilidades específicas identificadas dentro do campo jornalístico como fundamentais para compor as matérias etc. Em certo sentido trabalha-se dentro da perspectiva sintetizada por Moretzsohn ${ }^{6}$, que defende que o público seja o protagonista de seus próprios programas (sem a mediação do jornalista). Segundo a autora, esse tipo de enfoque não leva em conta que o público, ao apropriar-se dos meios, o faria provavelmente dentro de enquadramentos já estabelecidos pelos noticiários, ou seja, não falaria com a sua própria voz, que necessita de mediação para se fazer ouvir. Da mediação do jornalismo responsável, por exemplo.

Outro dado a ser levado em conta é a perspectiva de ampliação da compreensão da cidadania pelos jovens que participam da Viração, ou pelos que a consomem enquanto produto cultural. Não há pesquisas específicas sobre isso, mas é certo que a participação no Conselho Jovem reforça nos adolescentes a possibilidade de expressão e discussão de temas sociais amplos, municiando-os melhor, provavelmente, para intervenções futuras em outras instâncias.

\section{PRODUÇÃO}

No início, a Viração foi publicada pela Editora Alô Mundo, uma filial da Província dos Missionários Combonianos do Brasil, que também editavam a revista Sem Fronteiras. Por motivos econômicos, a editora deixou de publicar
6. MORETZSOHN, Sylvia Jornalismo, mediação, poder: considerações sobre o óbvio surpreendente. Brasília: UnB, 2003. Artigo apresentado no I Encontro de Professores de Jornalismo. 
ambas as revistas. Posteriormente, a Sem Fronteiras extinguiu-se e a Viração passou a ser publicada, a partir do número 8, pelo Projeto Viração, da Associação de Apoio a Meninas e Meninos da Região Sé de São Paulo, entidade que atua há mais de dez anos na defesa dos direitos de crianças, jovens e adolescentes da capital paulista. Também passou a ter sede própria, na região da Consolação, no centro de São Paulo.

O Projeto Editorial da revista informa que é uma publicação mensal com meta de tornar-se um projeto social impresso, pois, além de não ter fins lucrativos, propõe-se a ir além da impressão, desenvolvendo junto aos jovens atividades de comunicação e educação. Nestas, eles são identificados com protagonistas, tanto de fóruns de debates sobre educação, juventude e comunicação como de atividades como oficinas de jornal mural. Seu público é formado especialmente por jovens das escolas públicas (em função principalmente da distribuição), apesar de pretender atingir adolescentes de todas as camadas sociais.

O Projeto especifica ainda que a linha da revista tem um viés humanista, não sendo um veículo de comunicação moralista com o intuito de ensinar o jovem como pensar e agir em relação aos temas tratados. Sua linha editorial almeja defender valores que ajudem na educação de uma juventude consciente de seus direitos e interessada em cuidar do mundo. Por outro lado, propõe-se a não ser maniqueísta, dividindo o mundo entre mocinhos e bandidos. Sua proposta é fomentar o debate, tornando-se um fórum para o desenvolvimento de uma consciência de cidadania do indivíduo. O pressuposto é que o adolescente não aceite ser mandado nem manipulado, mas deseje descobrir, se possível, soluções para seus problemas, tirando as próprias conclusões e adotando posturas a respeito dos assuntos abordados. A Viração procura também aproximar o cotidiano da escola à realidade da vida, tratando o jovem como cidadão, e não como mero consumidor.

\section{DISTRIBUIÇÃO}

É realizada em todo o país por meio de assinaturas que podem ser processadas virtualmente pelo correio eletrônico (assinatura@revistaviracao.com.br) ou por correspondência. A Viração atinge o jovem da periferia de São Paulo, através da distribuição gratuita para escolas e entidades que atuam junto à juventude em diversas regiões da cidade. Via NCE, a revista foi distribuída para as escolas públicas dos Estados de Mato Grosso, Mato Grosso do Sul e Goiás, que participam do Projeto Educomradio.centro-oeste ${ }^{7}$, como também da cidade de São Paulo, integrante do Projeto Educom.radio ${ }^{8}$.

A sobrevivência da revista está ligada principalmente à possibilidade de captação de recursos (doações e patrocínios) e venda de anúncios, sendo que estes passam por um controle da adequação à linha editorial.

A situação financeira não é das mais confortáveis, mas alguns prêmios e

7. <http://www.usp.br/ educomradio/centro-oeste>.

8. <http://www.usp.br/ educomradio $>$. reconhecimentos externos têm contribuído para animar seus idealizadores, como o Valorização de Iniciativas Culturais da Secretaria de Cultura do Município 
de São Paulo, que concedeu a nota máxima para a Viração, entre mais de 600 projetos concorrentes. Em 2004, foi semifinalista do grande Prêmio Airton Senna de jornalismo, concorrendo com gigantes do mercado editorial voltado para jovens, como Capricho, revista MTV e encartes juvenis da Folha de S. Paulo e Correio Braziliense.

Em junho de 2004, ganhou o Prêmio Don Mario Pasini Comunicatore, em Roma, concedido pela Associazione Cuore Amico e a Agência de Notícias Misna. Em junho de 2005, segundo Relatório Mídia Jovem, da Agência de Notícias dos Direitos da Infância (Andi), Viração é a primeira no ranking entre as revistas voltadas para jovens, seguida da MTV, Capricho, Todateen e Atrevida. Em dezembro de 2005, ganhou o Prêmio Cidadania Mundial, concedido pela Comunidade Bahá'í do Brasil.

Durante todo o ano de 2007, Viração capacitou 300 alunos e professores de 100 escolas públicas do Ensino Médio para a produção de jornal mural. Trata-se de um projeto de incentivo à leitura patrocinado pela Secretaria de Cultura do Estado de São Paulo. A revista foi levada a essas escolas gratuitamente para ser utilizada como instrumento pedagógico em sala de aula e também para incentivar as escolas a criarem uma equipe de comunicação e de produção de jornais murais, a partir da experiência educomunicativa da Viração.

Também no mês de julho de 2007, a revista reativou a Agência ViraJovem de Notícias, com o intuito de levar a Educomunicação aos Jogos Pan-Americanos e trabalhar com as comunidades do Rio de Janeiro a partir de uma visão de quem, muitas vezes, é excluído do direito ao esporte e lazer. Daí surgiu a proposta do Projeto PapoPan, que envolveu cinqüenta jovens de diversas comunidades cariocas e profissionais de comunicação ${ }^{9}$.

Notícias, fotos, radioweb e videoweb foram publicados no site ${ }^{10}$ da Agência e foram reproduzidos por outros veículos de comunicação na base do princípio de copyleft, além do envio diário de um boletim para os sites parceiros e rádios comunitárias de todo o Brasil.

Manter ativa a Agência ViraJovem de Notícias não é uma tarefa fácil. Comunicação é coisa séria e de grande responsabilidade. Por isso, a equipe da Viração promove, diariamente, oficinas de comunicação entre os grupos de jovens participantes para que façam uma cobertura de qualidade e inovadora, protagonista, dos acontecimentos que eles mesmos estão presenciando.

\section{LINHA EDITORIAL}

A Viração tem como eixos editoriais os direitos do jovem cidadão, a diversidade cultural, étnica e religiosa, a educação para a não-violência e as diretrizes básicas do Ministério da Educação sobre ética, sexo, ambiente, direitos do jovem trabalhador. Traz em suas reportagens e seções assuntos relativos à realidade brasileira e de outros países, a defesa dos direitos humanos, a educação para a paz, a solidariedade entre os povos e o respeito ao pluralismo.
9. O projeto contou com a parceria do Observatório de Favelas, do Ministério do Desenvolvimento Social e Combate à Fome, do Ministério da Justiça e do Ministério dos Esportes; teve o apoio do Fundo das Nações Unidas para a Infância (Unicef), do Núcleo de Comunicação e Educação da Escola de Comunicações e Artes da Universidade de São Paulo (NCE-ECA-USP), da Agência de Notícias dos Direitos da Infância (Andi) e da Radiobrás.

10. <http://www.revistaviracao.org.br/agencia>. 
Os textos são curtos, de uma ou duas páginas normalmente, com intertítulos e olhos. Quando o assunto exige, há um texto principal seguido de subretrancas. Além disso, são apoiados por quadros explicativos, indicações para aprofundamento como o box Tá na Mão, gráficos, tabelas e mapas.

A revista procura ter uma

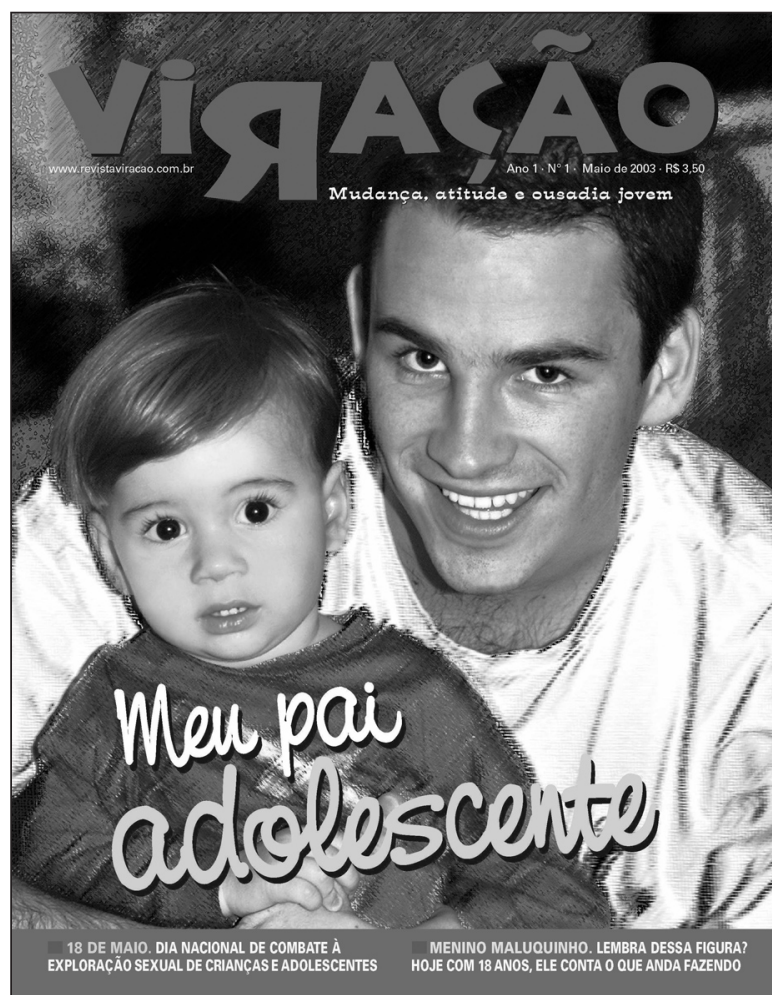
linguagem direta que chegue no jovem sem qualquer rodeio. Um dos colaboradores é o chargista Márcio Baraldi, Prêmio Vladimir Herzog de 2002, que faz propostas de personagens que alinham partes do editorial ou trilham uma história em quadrinhos.

As seções que a compõem são construídas a partir de uma idéia do que é ser jovem, buscando um diálogo com o público-alvo, tanto do ponto de vista semântico quanto do ponto de vista gráfico, o que é bastante perceptível nas editorias Galera repórter, que abrange entrevistas com personalidades jovens e adultas, procurando enfocar sempre o ser adolescente dos entrevistados; Sexo e Saúde, que aborda a afetividade, as transformações do corpo, com base em perguntas dos leitores e respostas de um especialista que possui habilidade em escrever para jovens; Vira ou não Vira, coluna produzida por jovens do ensino médio, em que o estudante passa o dia com um profissional da área na qual ele pretende seguir carreira, descrevendo a experiência para a revista. Também são privilegiadas seções que procuram dar voz ao jovem, como Entre Aspas (opiniões do leitor) e VirArte (poesias, charges, desenhos) e seções que buscam ligar o universo jovem ao mundo adulto, como Economês, Mais Igual (ligado à igualdade racial), Página Verde (ecologia), Parada Social (movimentos sociais) e Tesão (depoimentos sobre profissões). Sem esquecer daquelas facilmente identificadas com o universo jovem: No Escurinho (crítica de filmes) e Todos os Sons.

\section{PROTAGONISMO REAL}

A revista Viração institui-se em um momento de mudança em relação às ofertas tradicionais para o público jovem. Além da melhoria quantitativa e qualitativa da cobertura da mídia sobre os jovens, observa-se a sedimentação de vários projetos que colocam a criança e o adolescente no centro da produção midiática, 
não apenas como consumidores de mídia, mas como agentes de sua realização. Esses projetos, no entanto, ainda precisam de legitimidade social para garantir sua existência no mercado - e não apenas a partir de incentivos públicos.

Por outro lado, enfrentam as dificuldades de se produzir mídia com sujeitos sem especialização, tida como parâmetro não só nos veículos mercadológicos, mas também entre veículos alternativos. Essa característica aponta para um paradoxo: se o protagonismo real implica começar desde o jovem, como identifica Muñoz, ele tem que estar presente não apenas para sugerir as pautas e os temas, mas também em todo o processo de produção, já que aí que se definirá o enfoque e o enquadramento.

A revista, a partir da organização de seu Conselho Jovem, caminha em direção a essa possibilidade. A organização da pauta é apenas uma das atividades com as quais se envolvem os jovens, os quais estão presentes também em sua execução, mesmo que de forma bastante restrita. Por outro lado, faltam pesquisas sistemáticas sobre a relação da revista com seu público-alvo, que indique se a Viração está sendo realmente apropriada como instrumento de valorização do jovem e como fórum para o desenvolvimento de uma consciência de cidadania do indivíduo, como se propõe.

A possibilidade efetiva de realizar-se desd los jovenes, portanto, ainda está por ser aplicada, na revista e em todos os veículos que se propõem a trabalhar dentro do parâmetro do protagonismo radical. Tal possibilidade, ainda por ser construída, já se defronta com alguns entraves, como a concepção, amplamente defendida (mesmo nas hostes mais à esquerda do espectro social), de que o jornalismo é um empreendimento social que deve ser feito exclusivamente por profissionais formados dentro do métier ${ }^{11}$.

Resumo: A experiência relata e analisa o projeto da revista Viração, veículo que procura envolver os jovens dentro da noção de protagonismo infanto-juvenil. Composta por um Conselho Jovem que, além de propor pautas e avaliar a publicação, se envolve diretamente com a realização das matérias, a Viração é divulgada como um projeto social impresso. Discutem-se as possibilidades e dificuldades de apropriação pelos jovens de conceitos do jornalismo e de sua transformação efetiva em instrumento de resgate da cidadania, relacionando essa discussão aos movimentos da sociedade civil para se apropriar e interferir nos processos antes reservados exclusivamente a profissionais legitimados dentro do campo jornalístico.

Palavras-chave: revista Viração, protagonismo, projeto social impresso, produção midiática.
Abstract: The present paper analyses the project with Viração magazine, a media that aims to involve young adults within the notion of infantile-youth protagonism. Viração is published as a social printing project. It is composed of Youth Council that, besides proposing the subjects, evaluates it and gets involved directly on the making of the articles. There is a large discussion about the possibilities and difficulties of the appropriation by young adults of journalism concepts and its effective transformation into an instrument for rescuing their citizenship relating this discussion to the civil society movements for appropriation and interference in the processes previously related exclusively to professionals legitimated within the journalistic field.

Keywords: Viração magazine, protagonism, social printing project, midiatic production, and appropriation.
11. LAGO, Cláudia. O romantismo morreu? Viva - romantismo: éthos romântico no jornalismo. 2003. Tese de doutorado. Programa de Pós-Graduação em Ciências da Comunicação-ECA/USP, São Paulo, 2003. 